Canadian Science Publishing

Applied Physiology, Nutrition, and Metabolism Physiologie appliquée, nutrition et métabolisme

\title{
Body Composition and Energy Intake- Skeletal Muscle Mass is the Strongest Predictor of Food Intake in Obese Adolescents: The HEARTY Trial
}

\begin{tabular}{|r|l|}
\hline Journal: & Applied Physiology, Nutrition, and Metabolism \\
\hline Manuscript ID & apnm-2015-0479.R1 \\
\hline Manuscript Type: & Article \\
\hline Complete List of Authors: & $\begin{array}{l}\text { Cameron, Jameason; Children's Hospital of Eastern Ontario, Healthy Active } \\
\text { Living and Obesity } \\
\text { Sigal, Ronald; University of Calgary, } \\
\text { Kenny, Glen; University of Ottawa, } \\
\text { Alberga, Angela; University of Calgary, Werklund School of Education } \\
\text { Prud'Homme, Denis; Montfort Hospital } \\
\text { Phillips, Penny; The Ottawa Hospital Research Institute, Clinical } \\
\text { Epidemiology Program } \\
\text { Doucette, Steve; Dalhousie University, Capital District Health Authority } \\
\text { Community Health and Epidemiology } \\
\text { Goldfield, Gary; Childrens Hospital of Eastern Ontario }\end{array}$ \\
\hline Keyword: & $\begin{array}{l}\text { body composition, fat free mass < body composition, dietary intake < } \\
\text { energy regulation, adolescent obesity, magnetic resonance imaging }\end{array}$ \\
\hline &
\end{tabular}




\title{
Body Composition and Energy Intake- Skeletal Muscle Mass is the Strongest Predictor of Food Intake in Obese Adolescents: The HEARTY Trial
}

\author{
Cameron, Jameason $\mathrm{D}^{1,2}$, Sigal, Ronald $\mathrm{J}^{2,3,4}$, Kenny, Glen $\mathrm{P}^{2,4}$, Alberga, Angela $\mathrm{S}^{3}$, \\ Prud'homme, Denis ${ }^{2,5}$, Phillips, Penny ${ }^{4}$, Doucette, Steve ${ }^{6}$, Goldfield, Gary ${ }^{1,2}$ \\ ${ }^{1}$ Children's Hospital of Eastern Ontario Research Institute, Ottawa, ON, Canada; \\ ${ }^{2}$ University of Ottawa, Ottawa, ON, Canada; ${ }^{3}$ University of Calgary, Calgary, AB, \\ Canada; ${ }^{4}$ Clinical Epidemiology Program, Ottawa Hospital Research Institute, Ottawa, \\ ON, Canada; ${ }^{5}$ Institut de recherche de l'Hôpital Montfort, Ottawa, ON, Canada; ${ }^{6}$ \\ Dalhousie University, Halifax, NS, Canada
}

Address correspondence to: Gary Goldfield, Healthy Active Living \& Obesity (HALO) Research Group, CHEO Research Institute, 401 Smyth Rd., Ottawa, ON, K1H 8L1, CANADA, ggoldfield@ cheo.on.ca, 613-737-7600 ext. 3288.

\section{Running Title: Body composition and energy intake in obese adolescents}

Trial Registration: ClinicalTrials.Gov NCT00195858

http://clinicaltrials.gov/show/NCT00195858, September 12, 2005 (Funded by the Canadian Institutes of Health Research). 


\begin{abstract}
Purpose: There has been renewed interest in examining the relationship between specific components of energy expenditure and the overall influence on energy intake (EI). The purpose of this cross-sectional analysis was to determine the strongest metabolic and anthropometric predictors of EI. It was hypothesized that resting metabolic rate (RMR) and skeletal muscle mass would be the strongest predictors of EI in a sample of overweight and obese adolescents.
\end{abstract}

Methods: 304 post-pubertal adolescents (90 boys, 217 girls) aged $16.1( \pm 1.4)$ years with body mass index at or above the $95^{\text {th }}$ percentile for age and sex OR at or above the $85^{\text {th }}$ percentile plus an additional diabetes risk factor were measured for body weight, RMR (kcal/day) by indirect calorimetry, body composition by magnetic resonance imaging (fat free mass [FFM], skeletal muscle mass, fat mass [FM], and \%body fat), and EI (kcal/day) using 3-day food records.

Results: Body weight, RMR, FFM, skeletal muscle mass, and FM were all significantly correlated with EI $(\mathrm{p}<0.005)$. After adjusting the model for age, sex, height, and physical activity only FFM ( $\beta=21.9, p=0.007)$ and skeletal muscle mass $(\beta=25.8, p=0.02)$ remained as significant predictors of EI. FFM and skeletal muscle mass also predicted dietary protein and fat intake $(\mathrm{p}<0.05)$, but not carbohydrate intake.

Conclusions: With skeletal muscle mass being the best predictor of EI, our results support the hypothesis that the magnitude of the body's lean tissue is related to absolute levels of EI in a sample of inactive adolescents with obesity.

Key Words: Body composition, fat free mass, energy intake, adolescent obesity, magnetic resonance imaging, 


\section{Introduction}

Energy balance and energy homeostasis are theoretical concepts that provide a heuristic approach to understand feeding-one of the most integrated of all animal behaviors - and to further help guide an explanation of human obesity (Cameron and Doucet 2007). In practice, however, at the individual level humans do not balance energy intake and energy expenditure on a day-to-day basis (Dulloo et al. 2012), which results in a daily standard deviation of approximately $0.5 \%$ body weight (Garrow 1995). This deviation is due to the continuous use of energy over the course of the day combined with the episodic nature of feeding; therein there are a plethora of peripheral peptide and hormone signals released by the gastrointestinal tract (e.g. CCK, PYY $3-36$, GLP-1, etc.) and signals from adipose tissue (e.g. the adipokines leptin and adiponectin) that serve to adjust intake to changing demands. Although the cross-talk of peripheral tissues and organs with specific brain centers has been described in great detail in relation to appetite and body weight regulation (Berthoud 2004; Morton et al. 2006), there are still many questions that remain unanswered. To be sure, in the controlled setting of the laboratory and without exogenous pharmacologic administration of appetite hormones, very small effects or null findings are commonplace when trying to elucidate the role that these common appetite signals have in hunger, satiety, and energy balance in humans (Doucet and Cameron 2007; Gibbons et al. 2013; King et al. 2015; Sysko et al. 2013).

The recently developed concept of a "Dual Intervention Point Model" by Speakman et al. (2011) describes two distinct intervention points-low and high levels of body fatness - where between these points body fat plays a minimal role in the regulation of food intake (Speakman et al. 2011). Outside of these intervention points it is 
understood that at the low(ered) end of body fatness leptin signaling stimulates food intake and reduces energy expenditure, whereas, the opposite effects on feeding and energy expenditure are noted with high(er) body fatness, albeit to a lesser extent. Thus, under the circumstances described above, the drive for food may be better described by an equal but opposite drive to balance the energy used for the physiologic and metabolic activity of normal body functioning. In an effort to describe why, in a similar food environment, some individuals become obese while others do not, Speakman posits that there may be signals that are deficient—-specifically protein or micronutrients—which compel overconsumption at the individual level (Speakman 2014). Indeed, relative to carbohydrates, fats, and ethanol, dietary protein has been shown to produce the greatest effect on satiety and diet-induced thermogenesis in humans (Veldhorst et al. 2008), but it remains unclear and speculative whether we consume food to leverage a minimal level of protein. Correspondingly, in light of the literature showing no consistent relationship between physical activity energy expenditure and energy intake (Blundell et al. 2015; Donnelly et al. 2014; Martins et al. 2015) there has been a renewed interest in examining the relationship between other components of energy expenditure-particularly resting metabolic rate (RMR) and fat free mass (FFM) - and the overall influence on energy intake (Blundell et al. 2012b; Dulloo et al. 2015). It is well-accepted that the largest contributor to total energy expenditure is RMR, accounting for approximately $50-70 \%$ of the variance (Johnstone et al. 2005); by convention, FFM and fat mass (FM) account for approximately 60\% and 6\%, respectively, of that variance (Johnstone et al. 2005). Furthermore, a breakdown of contributions of energy expenditure arising from FFM have been estimated to be $20 \%$ brain, $20 \%$ liver, $11 \%$ heart, $9 \%$ gastrointestinal tract, and $20 \%$ 
from skeletal muscle (Elia 1992). In a recent 12 week study of appetite control in 41 overweight and obese men and women, a relationship between energy intake and energy expenditure was indeed found, whereby RMR (Caudwell et al. 2012) and to a lesser extent FFM (Blundell et al. 2012a) (but not FM), were significant predictors of daily energy intake and self-determined meal size. Although these findings made steps to confirm the hypothesis that individual changes in energy intake are related in changes in energy expenditure, because body composition was determined with air displacement plethysmography, it remained unclear which component of FFM contributed to the largest variance in energy intake.

The purpose of this study was to examine the cross-sectional relationships between RMR, FFM, skeletal muscle mass, FM, and self-reported daily food intake in sedentary overweight/obese adolescents. It was hypothesized that RMR and skeletal muscle mass would contribute to the physiological demand for energy and would thus be the strongest predictors of energy intake; a secondary hypothesis was that a relationship would exist between measures of skeletal muscle mass and self-selected protein intake.

\section{Materials and Methods}

\subsection{Subjects}

Participants were physically inactive, overweight or obese adolescents $(n=304 ; 90$ boys, 217 girls) aged 14-18 years (16.1 yrs \pm 1.4$)$, who volunteered for the Healthy Eating Aerobic and Resistance Training in Youth (HEARTY) trial conducted in Ottawa (Alberga et al. 2012; Sigal et al. 2014). This study was a secondary analysis of data from the HEARTY trial, which examined effects of exercise training on percent body fat measured by magnetic resonance imaging (MRI) (see (Alberga et al. 2012)). The main 
inclusion criteria were: sedentary post-pubertal (Tanner stages IV-V) adolescents aged 14-18 years with $\mathrm{BMI}>95^{\text {th }}$ percentile for age/sex $\mathrm{AND} / \mathrm{OR} \geq 85^{\text {th }}$ percentile for age/sex with an additional diabetes or cardiovascular disease risk factor (i.e. impaired glucose tolerance, fasting triglycerides $>1.7 \mathrm{mmol} / \mathrm{L}$, fasting plasma insulin $>105 \mathrm{pmol} / \mathrm{L}$, total cholesterol/HDL-C $>90$ th percentile, or first degree relative with type 2 diabetes), waist circumference $\geq 75^{\text {th }}$ percentile for age and sex. Exclusion criteria were regular or structured exercise or sport activities done more than twice a week for more than 20 minutes during the previous four months, diabetes mellitus, use of any performance enhancing medication, significant weight change (increase or decrease of $\geq 5 \%$ during the two months before enrollment), pregnancy at the start of the study, or intention to become pregnant in the next year, activity restrictions due to disease (unstable cardiac or pulmonary disease or significant arthritis), other illness (eating disorders/clinical depression) judged by the participant or study physician to make participation in this study inadvisable, and individuals planning to be away for more than 4 weeks during the summer.

Most of the sample (71\%) was Caucasian; $11 \%$ were African-Canadian, 3\% Hispanic, 3\% Asian, 3\% Arabic, 5\% mixed race, 2\% First Nations, and 2\% categorized as "other." The educational level of parents of most participants was high, with $78 \%$ of mothers and $67 \%$ of fathers having completed some university or community college. A parent or guardian was asked to co-sign the consent form of any participant below the age of 16 years. This study received approval from the Research Ethics Boards at the Children's Hospital of Eastern Ontario (protocol \#05/04E) and the Ottawa Hospital Research Institute (protocol \#2004219-01H). 


\subsection{Design and Procedure}

For the baseline assessments the research coordinator performed a complete medical, drug, and physical activity history as well as a physical examination. Clinical interviews were also performed to assess history of dieting, eating disorders, pubertal growth and development, and sedentary activities. If the potential participant reported any history of eating disorder (e.g. uncontrolled binging, binging and purging, anorexia) or clinical depression, they were excluded from the study. All participants and the individuals in their households most involved in food preparation attended an initial visit with the dietitian to discuss weight and diet history, fast food consumption and current eating habits. All participants received one-on-one counseling by a registered dietitian and the dietician worked with the participants to set achievable goals to promote healthy eating. Participants also attended a two-hour small group $(n=12)$ session covering various topics: barriers in achieving healthful eating and solutions to overcome them, taste panels of fruits and vegetables, label reading, healthful snacks, and healthier eating at fast food outlets (see (Alberga et al. 2012) for more details). Body weight, height, waist circumference, body composition and RMR were also measured.

\subsection{Measurements}

\subsubsection{Anthropometrics}

Height and weight were recorded with a manual stadiometer and scale, respectively, with participants wearing light clothing and no shoes. Waist circumference was measured at a level midway between the lowest rib and the top of the iliac crest, as previously described (Alberga et al. 2012). Body composition was assessed by MRI with a 1.5-T system (EchoSpeed, signal 11 version; GE Medical Systems). Participants lay 
prone for whole-body cross sectional images using protocols by Ross and colleagues

(Ross et al. 1992). The MRIs were analyzed using a Slice-OMatic ${ }^{\mathrm{TM}}$ software, version 4.3; Tomovision, Magog, Canada. FFM is defined as total lean tissue mass, which includes all fat-free skeletal muscle, organs, intestines, and bones, without adipose tissue. Total skeletal muscle mass is defined by fat-free skeletal muscle due to the absence of intramuscular fat included in the calculation. Visceral adipose tissue is the fat surrounding the internal organs, whereas, subcutaneous adipose tissue lies immediately below the dermis of the skin.

\subsubsection{Energy Intake: Estimated 3-Day Food Logs}

Under the supervision of a registered dietitian, energy intake was assessed using 3-day self-reported food logs. This method of assessing energy intake is called estimated food records, and is similar to the weighed food record approach except that quantification of food and drink is estimated and not weighed. Regarding the reliability of this measure, in a recent paper examining the magnitude of EI misreporting it was determined that there was no significant difference between the medians of percentage of misreporters when comparing three of the main methods of self-reported food intake: 24 hour recall, 3-and 7-day food logs, and weighed food records (underestimation of EI was 13.4\%, 12.2\%, and 18.0\%, respectively) (Poslusna et al. 2009). Furthermore, looking at the literature we can see agreement between 3- and 7-day food logs (12\% under-reporting (Taren et al. 1999) vs. 17\% under-reporting (Velthuis-te Wierik et al. 1995)), for example, thus while there is indeed a large variability not only in day-to-day feeding at the individual level and large variability at the inter-individual level as well, we argue that this is within an acceptable tolerance of variability with a sample size as large as the 
HEARTY sample. Adolescents were asked to complete their 3-day food logs in real time, right after eating, over two weekdays and one weekend day prior to the visit with the dietitian. Participants were instructed to record the quantity of all food and beverages consumed or by weight and to record methods of food preparation, brand names and ingredients of foods, and recipes of mixed dishes when possible. Completed food logs were discussed between the participant and the dietitian during the in-person visit for clarification of food details and amounts. Participants were counseled on appropriate portion sizes using food models supplied with a handout that described in detail how to measure food portions and if they did not have access to measuring tools (cups, spoons, etc.), they were advised to following the Canadian Diabetes Association's Handy Portion Guide included in the handout (www.diabetes.ca/Files/plan\%20your\%20portions.pdf). In order to increase accuracy in the 3-day food logs participants also attended one group nutrition session in which they learned to navigate food labels and fast food menus. The food logs were analyzed with food composition analysis software (The Food Processor SQL 2006, ESHA Research, Salem, OR) to determine total energy intake (average daily kcal) and separate macronutrient intake (grams) for carbohydrate, protein and fat for each participant. In most cases the days recorded were consecutive, including one weekend day and two week days; to be clear, some of the weekday reporting included nonconsecutive days. Intake of each nutrient class was averaged across the 3 days for analysis.

\subsubsection{Energy Expenditure}

Resting metabolic rate (RMR) was measured using an automated metabolic system (MOXUS Modular Metabolic System, AEI Technologies, Naperville, IL, USA) for a 20- 
minute data collection period. A plexiglass hood was placed over the paticipant's head through which fresh air was drawn for 30 minutes. The first and last 5 minutes of measurement were discarded, and the values of $\mathrm{VO} 2$ and $\mathrm{VCO} 2$ for the middle 20 minutes were averaged for the calculation of the rate of RMR. The Weir formula was used for the calculation of RMR (Weir 1949). In order to control for background physical activity, participants were required to wear pedometers (Yamax DIGIWALKER SW-700, Yamax Corporation, Tokyo, Japan) for one week during the same baseline testing session at which the food diaries were collected. Participants were also required to accompany the pedometer measurement with the recording of physical activities using the Past Day Physical Activity recall, which is a valid self-report measure of physical activity in youth (including obese youth) (Weston et al. 1997). The pedometer and the Past Day Physical Activity recall created a physical activity score that measured average physical activity and intensity, as described previously (Goldfield et al. 2012).

\subsection{Analytic Plan}

Baseline characteristics were summarized as means with standard deviation for continuous data and frequencies with percentages for categorical data. Linear regression analyses with parameter estimates were performed to examine the independent associations between energy intake (dependent variables: mean total $\mathrm{kcal}$ and macronutrient composition) and metabolic/anthropometric characteristics (independent variables: RMR, FFM and skeletal muscle mass, body weight, BMI, FM, \%body fat, visceral adipose tissue, and subcutaneous adipose tissue). Results were presented as unadjusted and adjusted parameter estimates adjusted for age, gender, height, and physical activity levels according to Dulloo et al. (2010) (Dulloo et al. 2010). 
Standardized $\beta$-coefficients were employed to show the relationship between mean 3-day energy intake, RMR, FFM, total skeletal muscle mass, and FM. Statistical analyses were conducted with SAS version 9.3, Cary, NC, and a two-tailed p-value $\leq 0.05$ was considered statistically significant.

\section{Results}

Participant characteristics are reported in Table 1. Results obtained from general linear models are summarized in Table 2 and illustrated in Figure 1. Linear regression analyses demonstrated that RMR, FFM, skeletal muscle mass, FM, and body weight were all significantly correlated with energy intake $(\mathrm{p}<0.05)$ (see Table 2 , panel A). After adjusting the model for age, sex, height, and physical activity only FFM $(\beta=21.9$ $\mathrm{p}=0.007)$ and skeletal muscle mass $(\beta=25.8, \mathrm{p}=0.02)$ remained as significant predictors of energy intake (see Table 2, panel B). Scatter plots with standardized $\beta$-coefficients (Figure 1) show the relationship between mean 3-day energy intake and FM $(\beta=1.55$, $\mathrm{p}=0.41), \operatorname{RMR}(\beta=0.18, \mathrm{p}=0.11)$, and total skeletal tissue $(\beta=25.2 \mathrm{p}=0.002)$. Examining the adjusted (age, sex, height, and physical activity) relationship between anthropometrics and specific macronutrient intake (see Table 2), significant positive relationships were found between protein and fat intake and FFM ( $p=0.0005$ and $\mathrm{p}=0.004$, respectively), total skeletal muscle ( $\mathrm{p}=0.003$ and $\mathrm{p}=0.02$, respectively), $\mathrm{RMR}$ ( $\mathrm{p}=0.03$ and $\mathrm{p}=0.02$, respectively), body weight $(\mathrm{p}=0.02$ and $\mathrm{p}=0.001$, respectively), and BMI ( $\mathrm{p}=0.04$ and $\mathrm{p}=0.003$, respectively). No significant findings were noted for carbohydrate intake.

\section{Discussion}


We investigated the relationship between components of metabolism as measured by indirect calorimetry and body composition as measured by MRI and mean 3-day selfreported energy intake in 304 inactive overweight or obese adolescent males and females. Our primary hypothesis was partially confirmed in that skeletal muscle mass was the strongest predictor of energy intake even after adjustment for age, sex, height, and physical activity levels, whereas RMR was not significantly related to energy intake under these same adjustments (Figure 1). Our secondary hypothesis was confirmed in that several anthropometric variables (primarily skeletal muscle mass and FFM), excluding fat mass or specific fat depots, were positively related to both dietary protein and fat intake (Table 2).

Previous research has found a strong correlation between RMR and FFM in adults over a broad range of body weights and activity levels, but similarly robust data have not been collected in youth or adolescents (Cunningham 1991). It is less clear how differences in body composition may predict energy intake either at an individual meal or over the course of days to weeks. An appetite mechanism driven by the demands for the growth of lean tissue in the developing child was discussed in great detail over two decades ago (Millward 1995; Webster 1993). These hypotheses gained traction with the idea of a 'proteinstat' when Dulloo et al. (1996) re-examined data from the Minnesota Semi-Starvation Experiment (Keys et al. 1950). They found during the ad libitum refeeding phase after semi-starvation that there was chronic hyperphagia continuing past the catch-up of baseline adiposity and lasting until basal levels of FFM were regained (Dulloo et al. 1996). In our sample of physically inactive overweight and obese adolescent males and females we indeed found that skeletal muscle mass and FFM 
predicted energy intake. For each $1 \mathrm{~kg}$ increase in those tissues, there were increases in average daily caloric intake of $22 \mathrm{kcal}$ and $26 \mathrm{kcal}$, respectively (see Table 2). Our findings are in agreement with those found in a study of active lean adolescents $(n=1450$, mean age 14 years) showing overall FFM (estimated with bioelectric impedance and air displacement plethysmography) was positively related to energy intake (Cuenca-Garcia et al. 2014), but differed from those in a study of approximately 500 boys and girls (aged 11-14 years) which showed no relationship between FFM (estimated using bioelectric impedance) and energy intake (Fulton et al. 2009). A strength of our study is that we measured body composition with MRI, which is a more accurate measure than bioelectric impedance or air displacement plethysmography, which were used in the two abovementioned studies. MRI is the most powerful and comprehensive imaging tool for FM and FFM quantification in part because bioelectric impedance and air displacement plethysmography are indirect techniques, which only estimate total and/or regional fat, and unlike MRI cannot differentiate between visceral adipose tissue and subcutaneous adipose tissue, nor can they accurately partition FFM from lean soft tissue (Hu et al. 2011). Although we did not find any relationship between FM (including visceral adipose tissue and subcutaneous adipose tissue) and energy intake (see Table 2, panel B) this does not imply that adipose tissue has no role in appetite, as adipokines have clearly been shown to impact feeding behavior in animals and humans (Ahima 2006). Furthermore, an example of the cross-talk between adipokines and myokines (Trayhurn et al. 2011), where leptin has recently been shown to influence skeletal muscle mass by inhibiting myofibrillar protein degradation in the mouse (Sainz et al. 2009), is worth noting. Taken together, we demonstrate that, similar to several other studies of adults (Blundell et al. 
2012b; Caudwell et al. 2013; Kien and Ugrasbul 2004) and a limited number of studies in youth and adolescents (Cuenca-Garcia et al. 2014; Weise et al. 2014), the positive relationship between metabolically active FFM and energy intake may indeed reflect a physiological demand for energy. Notwithstanding, the lack of association of FM and energy intake is not evidence of a lack of functional roles in the signaling of energy homeostasis.

Examining the secondary hypothesis that FFM or specifically skeletal muscle mass would be related to protein intake, we did indeed find a significant positive relationship in our sample of overweight/obese adolescents (Table 2). This relationship does not, however, provide direct evidence for the existence of a proteinstat nor does it prove that there are myokines driving appetite and feeding behaviour. The recently developed concept of a "Dual Intervention Point Model" by Speakman et al. (2011) describes two distinct intervention points_-low and high levels of body fatness-where between these points body fat plays a minimal role in the regulation of food intake (Speakman et al. 2011). Outside of these intervention points it is understood that at the low(ered) end of body fatness leptin signaling stimulates food intake and reduces energy expenditure, whereas, the opposite effects on feeding and energy expenditure are noted with high(er) body fatness, albeit to a lesser extent. Thus, under the circumstances described above, the drive for food may be better described by an equal but opposite drive to balance the energy used for the physiologic and metabolic activity of normal body functioning. In an effort to describe why, in a similar food environment, some individuals become obese while others do not, Speakman posits that there may be signals that are deficientspecifically protein or micronutrients — which compel overconsumption at the individual 
level (Speakman 2014). The mechanisms and the afferent signals for a proteinstat remain unknown although it is likely that the answer could be found by experimentally examining amino acid net flow from the free pool into skeletal muscle protein (Millward 1995). If the net flow of amino acids into skeletal muscle protein is greater than ingested dietary protein one would conclude that hunger and appetite would be stimulated by a sensor-afferent pathway. One candidate for the central sensing of dietary protein has recently been discovered in a mouse model where the authors describe a role for the fat mass and obesity associated gene (FTO) in the coupling of amino acid levels to mammalian target of rapamycin complex 1 signaling (Gulati et al. 2013), suggesting a possible target for future research on potential nutrient sensing mechanisms.

As with any measure of self-reported feeding there is the potential of dietary underreporting (Karelis et al. 2010) and this cannot be discounted as a limitation, but it has been shown that youth and adolescents underreport to a lesser degree than adults (Champagne et al. 1998). The fact that our sample consisted of males and females with overweight or obesity also requires further caution when interpreting the energy intake data, as it is well documented that obese underreport more than lean adults (Briefel et al. 1997; Hirvonen et al. 1997) and adolescents (Bratteby et al. 1998) and females underreport more than males (Dwyer et al. 2003). For large-scale studies, however, food logs (involving weighing, or as in the current study, quantifying with household measures) have been considered the most accurate and feasible method of dietary assessment (Barrett-Connor 1991; Hill and Davies 2001), especially due to the high costs associated with isolating participants in a ward in order to establish very controlled feeding conditions. The cross-sectional nature of the study limits the ability to make 
causal inferences with respect to metabolic and anthropometric predictors of energy intake variables. We also cannot discount the role that diabetes risk factors as inclusion criteria may have had on energy intake; the role of nutrient sensing, particularly with elevated glycemia and insulinemia, may have acted as an extraneous variable influencing appetite and energy intake (Hamr et al. 2015). A major strength of the present study is that body composition was measured with MRI, which allowed for the accurate assessment not only of FM and total FFM, but also skeletal muscle mass. We were able to show that higher skeletal muscle mass was associated with increased dietary energy consumption. In contrast, previous studies in which body composition was assessed with air displacement plethysmography (Blundell et al. 2012a; Caudwell et al. 2013; CuencaGarcia et al. 2014), were unable to differentiate skeletal muscle mass from other lean tissue. The fact that $32 \%$ of North American youth are either overweight or obese (Ogden et al. 2014; Roberts et al. 2012) indicates that there is still a need to understand not only the behavioral factors involved in the act of eating, but also the physiological signals that promote feeding and overconsumption. In the current study we found that skeletal muscle mass was the best predictor of energy intake, supporting the hypothesis that the body's lean tissue is related to absolute levels of energy intake in a sample of overweight or obese adolescents. In a recent review examining whether physical activity-induced energy expenditure predicts energy intake in children and adolescents (Thivel et al. 2013), the conclusion was that the energy expended from activities ranging from passive video gaming to moderate to vigorous exercise likely did not drive energy intake, but overconsumption and weight gain may be promoted via other pathways (e.g. short sleep duration (Hjorth et al. 2014), low dietary calcium intake (Tremblay 2008), pollutants 
(Pelletier et al. 2003), etc.). Indeed, school-based physical activity interventions have consistently shown that physical activity energy expenditure does not reliably impact energy intake nor overall body weight or fatness (Fremeaux et al. 2011; Harris et al. 2009; Metcalf et al. 2008). Such conclusions highlight the need to further examine the relationship between skeletal muscle mass and energy intake in the context of energy balance and body weight regulation.

\section{Conflict of Interest}

The authors declare that there are no conflicts of interest.

\section{Acknowledgements}

The HEARTY trial was supported by a grant from the Canadian Institutes of Health Research (grant MCT-71979). Dr. Sigal is supported by a Health Senior Scholar award from Alberta Innovates-Health Solutions, and was supported by a Research Chair from the Ottawa Hospital Research Institute during part of this trial. Dr. Angela S. Alberga was supported by a Doctoral Student Research Award from the Canadian Diabetes Association and an Eyes High Postdoctoral Fellowship from the University of Calgary. Dr. Glen Kenny was supported by a University Research Chair. Dr. Goldfield was supported by a New Investigator Award from the Canadian Institutes of Health Research for part of the trial, and subsequently by an Endowed Research Scholarship from the Children's Hospital of Eastern Ontario Volunteer Association Board. Colleen Gilchrist and Pascale Messier were the main dietitians for the trial. Tina Leech and Marie-Josée Cyr were also dietitians who worked with participants. Kelley Phillips analyzed all of the 3-day food logs. 


\section{References}

Ahima, R.S. 2006. Adipose tissue as an endocrine organ. Obesity (Silver Spring, Md. 14 Suppl 5(242S-249S.

Alberga, A.S., Goldfield, G.S., Kenny, G.P., Hadjiyannakis, S., Phillips, P., Prud'homme, D., Tulloch, H., Gougeon, R., Wells, G.A., and Sigal, R.J. 2012. Healthy Eating, Aerobic and Resistance Training in Youth (HEARTY): study rationale, design and methods. Contemporary clinical trials. 33(4): 839-847.

Barrett-Connor, E. 1991. Nutrition epidemiology: how do we know what they ate? The American journal of clinical nutrition. 54(182S-187S.

Berthoud, H.R. 2004. Mind versus metabolism in the control of food intake and energy balance. Physiology \& behavior. 81(5): 781-793.

Blundell, J., Caudwell, P., Gibbons, C., Hopkins, M., Naslund, E., King, N., and Finlayson, G. 2012a. Body composition and appetite: fat-free mass (but not fat mass or BMI) is positively associated with self-determined meal size and daily energy intake in humans. The British journal of nutrition. 107(445-449.

Blundell, J.E., Gibbons, C., Caudwell, P., Finlayson, G., and Hopkins, M. 2015. Appetite control and energy balance: impact of exercise. Obes Rev. 16 Suppl 1(67-76.

Blundell, J.E., Caudwell, P., Gibbons, C., Hopkins, M., Naslund, E., King, N., and Finlayson, G. 2012b. Role of resting metabolic rate and energy expenditure in hunger and appetite control: a new formulation. Disease models \& mechanisms. 5(5): 608-613.

Bratteby, L.E., Sandhagen, B., Fan, H., Enghardt, H., and Samuelson, G. 1998. Total energy expenditure and physical activity as assessed by the doubly labeled water method in Swedish adolescents in whom energy intake was underestimated by 7-d diet records. The American journal of clinical nutrition. 67(5): 905-911.

Briefel, R.R., Sempos, C.T., McDowell, M.A., Chien, S., and Alaimo, K. 1997. Dietary methods research in the third National Health and Nutrition Examination Survey: underreporting of energy intake. The American journal of clinical nutrition. 65(4 Suppl): 1203S-1209S.

Cameron, J. and Doucet, E. 2007. Getting to the bottom of feeding behaviour: who's on top? Appl Physiol Nutr Metab. 32(2): 177-189.

Caudwell, P., Finlayson, G., Gibbons, C., Hopkins, M., King, N., Naslund, E., and Blundell, J.E. 2012. Resting metabolic rate is associated with hunger, selfdetermined meal size, and daily energy intake and may represent a marker for appetite. The American journal of clinical nutrition. 97(1): 7-14.

Caudwell, P., Finlayson, G., Gibbons, C., Hopkins, M., King, N., Naslund, E., and Blundell, J.E. 2013. Resting metabolic rate is associated with hunger, selfdetermined meal size, and daily energy intake and may represent a marker for appetite. The American journal of clinical nutrition. 97(1): 7-14.

Champagne, C.M., Baker, N.B., DeLany, J.P., Harsha, D.W., and Bray, G.A. 1998. Assessment of energy intake underreporting by doubly labeled water and observations on reported nutrient intakes in children. Journal of the American Dietetic Association. 98(4): 426-433.

Cuenca-Garcia, M., Ortega, F.B., Ruiz, J.R., Labayen, I., Moreno, L.A., Patterson, E., Vicente-Rodriguez, G., Gonzalez-Gross, M., Marcos, A., Polito, A., Manios, Y., 
Beghin, L., Huybrechts, I., Wastlund, A., Hurtig-Wennlof, A., Hagstromer, M., Molnar, D., Widhalm, K., Kafatos, A., De Henauw, S., Castillo, M.J., Gutin, B., and Sjostrom, M. 2014. More physically active and leaner adolescents have higher energy intake. The Journal of pediatrics. 164(1): 159-166 e152.

Cunningham, J.J. 1991. Body composition as a determinant of energy expenditure: a synthetic review and a proposed general prediction equation. The American journal of clinical nutrition. 54(6): 963-969.

Donnelly, J.E., Herrmann, S.D., Lambourne, K., Szabo, A.N., Honas, J.J., and Washburn, R.A. 2014. Does increased exercise or physical activity alter ad-libitum daily energy intake or macronutrient composition in healthy adults? A systematic review. PloS one. 9(1): e83498.

Doucet, E. and Cameron, J. 2007. Appetite control after weight loss: what is the role of bloodborne peptides? Appl Physiol Nutr Metab. 32(3): 523-532.

Dulloo, A.G., Jacquet, J., and Girardier, L. 1996. Autoregulation of body composition during weight recovery in human: the Minnesota Experiment revisited. Int J Obes Relat Metab Disord. 20(5): 393-405.

Dulloo, A.G., Jacquet, J., Montani, J.P., and Schutz, Y. 2012. Adaptive thermogenesis in human body weight regulation: more of a concept than a measurable entity? Obes Rev. 13 Suppl 2(105-121.

Dulloo, A.G., Jacquet, J., Montani, J.P., and Schutz, Y. 2015. How dieting makes the lean fatter: from a perspective of body composition autoregulation through adipostats and proteinstats awaiting discovery. Obes Rev. 16 Suppl 1(25-35.

Dulloo, A.G., Jacquet, J., Solinas, G., Montani, J.P., and Schutz, Y. 2010. Body composition phenotypes in pathways to obesity and the metabolic syndrome. International journal of obesity (2005). 34 Suppl 2(S4-17.

Dwyer, J., Picciano, M.F., and Raiten, D.J. 2003. Estimation of usual intakes: What We Eat in America-NHANES. The Journal of nutrition. 133(2): 609S-623S.

Elia, M. 1992. Organ and tissue contribution to metabolic rate. In Energy Metabolism: Tissue Determinants and Cellular Corollaries. Edited by J. Kinney and H. Tucker. Raven Press Ltd., New York, NY. pp. 61-80.

Fremeaux, A.E., Mallam, K.M., Metcalf, B.S., Hosking, J., Voss, L.D., and Wilkin, T.J. 2011. The impact of school-time activity on total physical activity: the activitystat hypothesis (EarlyBird 46). International journal of obesity (2005). 35(10): 1277 1283.

Fulton, J.E., Dai, S., Steffen, L.M., Grunbaum, J.A., Shah, S.M., and Labarthe, D.R. 2009. Physical activity, energy intake, sedentary behavior, and adiposity in youth. American journal of preventive medicine. 37(1 Suppl): S40-49.

Garrow, J.S. 1995. Penalties of shifting weight. BMJ (Clinical research ed. 311(7021): 1653-1654.

Gibbons, C., Caudwell, P., Finlayson, G., Webb, D.L., Hellstrom, P.M., Naslund, E., and Blundell, J.E. 2013. Comparison of postprandial profiles of ghrelin, active GLP-1, and total PYY to meals varying in fat and carbohydrate and their association with hunger and the phases of satiety. The Journal of clinical endocrinology and metabolism. 98(5): E847-855.

Goldfield, G.S., Saunders, T.J., Kenny, G.P., Hadjiyannakis, S., Phillips, P., Alberga, A.S., Tremblay, M.S., and Sigal, R.J. 2012. Screen viewing and diabetes risk 
factors in overweight and obese adolescents. American journal of preventive medicine. 44(4 Suppl 4): S364-370.

Gulati, P., Cheung, M.K., Antrobus, R., Church, C.D., Harding, H.P., Tung, Y.C., Rimmington, D., Ma, M., Ron, D., Lehner, P.J., Ashcroft, F.M., Cox, R.D., Coll, A.P., O'Rahilly, S., and Yeo, G.S. 2013. Role for the obesity-related FTO gene in the cellular sensing of amino acids. Proceedings of the National Academy of Sciences of the United States of America. 110(7): 2557-2562.

Hamr, S.C., Wang, B., Swartz, T.D., and Duca, F.A. 2015. Does nutrient sensing determine how we "see" food? Current diabetes reports. 15(6): 604.

Harris, K.C., Kuramoto, L.K., Schulzer, M., and Retallack, J.E. 2009. Effect of schoolbased physical activity interventions on body mass index in children: a metaanalysis. Cmaj. 180(7): 719-726.

Hill, R.J. and Davies, P.S. 2001. The validity of self-reported energy intake as determined using the doubly labelled water technique. The British journal of nutrition. 85(4): 415-430.

Hirvonen, T., Mannisto, S., Roos, E., and Pietinen, P. 1997. Increasing prevalence of underreporting does not necessarily distort dietary surveys. European journal of clinical nutrition. 51(5): 297-301.

Hjorth, M.F., Quist, J.S., Andersen, R., Michaelsen, K.F., Tetens, I., Astrup, A., Chaput, J.P., and Sjodin, A. 2014. Change in sleep duration and proposed dietary risk factors for obesity in Danish school children. Pediatric obesity. 9(6): e156-159.

Hu, H.H., Nayak, K.S., and Goran, M.I. 2011. Assessment of abdominal adipose tissue and organ fat content by magnetic resonance imaging. Obes Rev. 12(5): e504515.

Johnstone, A.M., Murison, S.D., Duncan, J.S., Rance, K.A., and Speakman, J.R. 2005. Factors influencing variation in basal metabolic rate include fat-free mass, fat mass, age, and circulating thyroxine but not sex, circulating leptin, or triiodothyronine. The American journal of clinical nutrition. 82(5): 941-948.

Karelis, A.D., Lavoie, M.E., Fontaine, J., Messier, V., Strychar, I., Rabasa-Lhoret, R., and Doucet, E. 2010. Anthropometric, metabolic, dietary and psychosocial profiles of underreporters of energy intake: a doubly labeled water study among overweight/obese postmenopausal women--a Montreal Ottawa New Emerging Team study. European journal of clinical nutrition. 64(1): 68-74.

Keys, A., Brozek, J., Henschel, A., Mickelsen, O., and Taylor, H. (1950). The Biology of Human Starvation. St.Paul, Minnesota: North Central Publishing Company.

Kien, C.L. and Ugrasbul, F. 2004. Prediction of daily energy expenditure during a feeding trial using measurements of resting energy expenditure, fat-free mass, or Harris-Benedict equations. The American journal of clinical nutrition. 80(4): 876880.

King, J.A., Garnham, J.O., Jackson, A.P., Kelly, B.M., Xenophontos, S., and Nimmo, M.A. 2015. Appetite-regulatory hormone responses on the day following a prolonged bout of moderate-intensity exercise. Physiology \& behavior. 141(2331.

Martins, C., Stensvold, D., Finlayson, G., Holst, J., Wisloff, U., Kulseng, B., Morgan, L., and King, N.A. 2015. Effect of moderate- and high-intensity acute exercise on 
appetite in obese individuals. Medicine and science in sports and exercise. 47(1): 40-48.

Metcalf, B.S., Voss, L.D., Hosking, J., Jeffery, A.N., and Wilkin, T.J. 2008. Physical activity at the government-recommended level and obesity-related health outcomes: a longitudinal study (Early Bird 37). Archives of disease in childhood. 93(9): 772-777.

Millward, D.J. 1995. A protein-stat mechanism for regulation of growth and maintenance of the lean body mass. Nutrition research reviews. 8(1): 93-120.

Morton, G.J., Cummings, D.E., Baskin, D.G., Barsh, G.S., and Schwartz, M.W. 2006. Central nervous system control of food intake and body weight. Nature. 443(7109): 289-295.

Ogden, C.L., Carroll, M.D., Kit, B.K., and Flegal, K.M. 2014. Prevalence of childhood and adult obesity in the United States, 2011-2012. Jama. 311(8): 806-814.

Pelletier, C., Imbeault, P., and Tremblay, A. 2003. Energy balance and pollution by organochlorines and polychlorinated biphenyls. Obes Rev. 4(1): 17-24.

Poslusna, K., Ruprich, J., de Vries, J.H., Jakubikova, M., and van't Veer, P. 2009. Misreporting of energy and micronutrient intake estimated by food records and 24 hour recalls, control and adjustment methods in practice. The British journal of nutrition. 101 Suppl 2(S73-85.

Roberts, K.C., Shields, M., de Groh, M., Aziz, A., and Gilbert, J.A. 2012. Overweight and obesity in children and adolescents: results from the 2009 to 2011 Canadian Health Measures Survey. Health reports. 23(3): 37-41.

Ross, R., Leger, L., Morris, D., de Guise, J., and Guardo, R. 1992. Quantification of adipose tissue by MRI: relationship with anthropometric variables. J Appl Physiol (1985). 72(2): 787-795.

Sainz, N., Rodriguez, A., Catalan, V., Becerril, S., Ramirez, B., Gomez-Ambrosi, J., and Fruhbeck, G. 2009. Leptin administration favors muscle mass accretion by decreasing FoxO3a and increasing PGC-1alpha in ob/ob mice. PloS one. 4(9): e6808.

Sigal, R.J., Alberga, A.S., Goldfield, G.S., Prud'homme, D., Hadjiyannakis, S., Gougeon, R., Phillips, P., Tulloch, H., Malcolm, J., Doucette, S., Wells, G.A., Ma, J., and Kenny, G.P. 2014. Effects of aerobic training, resistance training, or both on percentage body fat and cardiometabolic risk markers in obese adolescents: the healthy eating aerobic and resistance training in youth randomized clinical trial. JAMA pediatrics. 168(11): 1006-1014.

Speakman, J.R. 2014. If body fatness is under physiological regulation, then how come we have an obesity epidemic? Physiology (Bethesda, Md. 29(2): 88-98.

Speakman, J.R., Levitsky, D.A., Allison, D.B., Bray, M.S., de Castro, J.M., Clegg, D.J., Clapham, J.C., Dulloo, A.G., Gruer, L., Haw, S., Hebebrand, J., Hetherington, M.M., Higgs, S., Jebb, S.A., Loos, R.J., Luckman, S., Luke, A., Mohammed-Ali, V., O'Rahilly, S., Pereira, M., Perusse, L., Robinson, T.N., Rolls, B., Symonds, M.E., and Westerterp-Plantenga, M.S. 2011. Set points, settling points and some alternative models: theoretical options to understand how genes and environments combine to regulate body adiposity. Disease models \& mechanisms. 4(6): 733745. 
Sysko, R., Devlin, M.J., Schebendach, J., Tanofsky-Kraff, M., Zimmerli, E., Korner, J., Yanovski, J.A., Zitsman, J.L., and Walsh, B.T. 2013. Hormonal responses and test meal intake among obese teenagers before and after laparoscopic adjustable gastric banding. The American journal of clinical nutrition. 98(5): 1151-1161.

Taren, D.L., Tobar, M., Hill, A., Howell, W., Shisslak, C., Bell, I., and Ritenbaugh, C. 1999. The association of energy intake bias with psychological scores of women. European journal of clinical nutrition. 53(7): 570-578.

Thivel, D., Aucouturier, J., Doucet, E., Saunders, T.J., and Chaput, J.P. 2013. Daily energy balance in children and adolescents. Does energy expenditure predict subsequent energy intake? Appetite. 60(1): 58-64.

Trayhurn, P., Drevon, C.A., and Eckel, J. 2011. Secreted proteins from adipose tissue and skeletal muscle - adipokines, myokines and adipose/muscle cross-talk. Archives of physiology and biochemistry. 117(2): 47-56.

Tremblay, A. 2008. Dairy and weight loss hypothesis. Nutrition reviews. 66(9): 544-545; author reply 546-547.

Veldhorst, M., Smeets, A., Soenen, S., Hochstenbach-Waelen, A., Hursel, R., Diepvens, K., Lejeune, M., Luscombe-Marsh, N., and Westerterp-Plantenga, M. 2008. Protein-induced satiety: effects and mechanisms of different proteins. Physiology \& behavior. 94(2): 300-307.

Velthuis-te Wierik, E.J., Westerterp, K.R., and van den Berg, H. 1995. Impact of a moderately energy-restricted diet on energy metabolism and body composition in non-obese men. Int J Obes Relat Metab Disord. 19(5): 318-324.

Webster, A.J. 1993. Energy partitioning, tissue growth and appetite control. The Proceedings of the Nutrition Society. 52(1): 69-76.

Weir, J.B. 1949. New methods for calculating metabolic rate with special reference to protein metabolism. J Physiol. 109(1-2): 1-9.

Weise, C.M., Hohenadel, M.G., Krakoff, J., and Votruba, S.B. 2014. Body composition and energy expenditure predict ad-libitum food and macronutrient intake in humans. International journal of obesity (2005). 38(2): 243-251.

Weston, A.T., Petosa, R., and Pate, R.R. 1997. Validation of an instrument for measurement of physical activity in youth. Medicine and science in sports and exercise. 29(1): 138-143. 
Table 1. Descriptive characteristics of the Healthy Eating Aerobic and Resistance Training in Youth (HEARTY) sample.

\begin{tabular}{lc}
\hline Characteristic & Mean (SD) \\
\hline Anthropometric & $168(7.4)$ \\
Height $(\mathrm{cm})$ & $98(16.9)$ \\
Weight $(\mathrm{kg})$ & $34.6(4.5)$ \\
Body Mass Index $\left(\mathrm{kg} / \mathrm{m}^{2}\right)$ & $49.5(5.6)$ \\
Total \% Body Fat & $47.6(10.8)$ \\
Total Fat $(\mathrm{kg})$ & $48(8.4)$ \\
Fat Free Mass $(\mathrm{kg})$ & $24.7(5.4)$ \\
Total Skeletal Muscle $(\mathrm{kg})$ & \\
Energy Intake & $2187(639)$ \\
Total caloric intake (kcal/day) & $84(27)$ \\
Protein (g) & $280(88)$ \\
Carbohydrates (g) & $84(32)$ \\
Fat $(\mathrm{g})$ & \\
Energy Expenditure & $2025(414)$ \\
Resting Metabolic Rate (kcal/day) & \\
\hline Note: SD=standard deviation; MRI=magnetic resonance imaging; kcal=kilocalories; \\
cm=centimeters; kg=kilograms; g=grams
\end{tabular}


Table 2. Linear regression analysis demonstrating the independent associations between subjects' characteristics (independent variables) and energy intake (dependent variables), presented unadjusted and adjusted for age, sex, height, and physical activity.

\begin{tabular}{|c|c|c|c|c|c|c|c|c|}
\hline \multirow[t]{2}{*}{ Panel A } & \multicolumn{8}{|c|}{ Unadjusted } \\
\hline & \multicolumn{2}{|c|}{ Energy Intake (kcal) } & \multicolumn{2}{|c|}{ Protein (grams) } & \multicolumn{2}{|c|}{ Fat (grams) } & \multicolumn{2}{|c|}{ Carbohydrate (grams) } \\
\hline Baseline & $\begin{array}{c}\text { Parameter } \\
\text { estimate } \\
(\mathrm{SE})\end{array}$ & P-value & $\begin{array}{c}\text { Parameter } \\
\text { estimate } \\
(\mathrm{SE})\end{array}$ & P-value & $\begin{array}{c}\text { Parameter } \\
\text { estimate } \\
\text { (SE) }\end{array}$ & P-value & $\begin{array}{c}\text { Parameter } \\
\text { estimate } \\
\text { (SE) }\end{array}$ & P-value \\
\hline Fat Free Mass (kg) & $21.1(4.2)$ & $<0.0001$ & $1.3(0.2)$ & $<0.0001$ & $0.9(0.2)$ & $<0.0001$ & $1.8(0.6)$ & 0.003 \\
\hline Total Skeletal Muscle (kg) & $31.4(6.6)$ & $<0.0001$ & $1.9(0.3)$ & $<0.0001$ & $1.4(0.3)$ & $<0.0001$ & $2.8(0.9)$ & 0.003 \\
\hline RMR (kcal/day) & $0.3(0.09)$ & 0.0003 & $0.02(0)$ & $<0.0001$ & $0.02(0)$ & 0.0001 & $0.02(0.01)$ & 0.08 \\
\hline Body Weight (kg) & $8.0(2.1)$ & 0.0002 & $0.5(0.09)$ & $<0.0001$ & $0.5(0.1)$ & $<0.0001$ & $0.4(0.3)$ & 0.16 \\
\hline $\operatorname{BMI}\left(\mathrm{kg} / \mathrm{m}^{2}\right)$ & $18.7(8.2)$ & 0.02 & $1.1(0.3)$ & 0.0008 & $1.5(0.4)$ & 0.0002 & $0.1(1.1)$ & 0.92 \\
\hline Fat Mass (kg) & $5.8(3.4)$ & 0.09 & $0.3(0.1)$ & 0.02 & $0.5(0.2)$ & 0.003 & $-0.07(0.5)$ & 0.89 \\
\hline$\%$ body fat & $-12.8(6.7)$ & 0.05 & $-0.8(0.3)$ & 0.004 & $-0.2(0.3)$ & 0.62 & $-2.2(0.9)$ & 0.02 \\
\hline SAT (kg) & $4.5(3.9)$ & 0.25 & $0.3(0.2)$ & 0.08 & $0.5(0.2)$ & 0.02 & $-0.2(0.5)$ & 0.68 \\
\hline VAT (kg) & $241.2(67.5)$ & 0.0004 & $12.4(2.8)$ & $<0.0001$ & $13.7(3.3)$ & $<0.0001$ & $16.4(9.5)$ & 0.08 \\
\hline
\end{tabular}


Table 2. continued

\begin{tabular}{|c|c|c|c|c|c|c|c|c|}
\hline \multirow[t]{2}{*}{ Panel B } & \multicolumn{8}{|c|}{ Adjusted (age, gender, height, and physical activity) } \\
\hline & \multicolumn{2}{|c|}{ Energy Intake (kcal) } & \multicolumn{2}{|c|}{ Protein (grams) } & \multicolumn{2}{|c|}{ Fat (grams) } & \multicolumn{2}{|c|}{ Carbohydrate (grams) } \\
\hline Baseline & $\begin{array}{l}\text { Parameter } \\
\text { estimate } \\
\text { (SE) }\end{array}$ & P-value & $\begin{array}{c}\text { Parameter } \\
\text { estimate } \\
\text { (SE) }\end{array}$ & P-value & $\begin{array}{c}\text { Parameter } \\
\text { estimate } \\
\text { (SE) }\end{array}$ & P-value & $\begin{array}{c}\text { Parameter } \\
\text { estimate } \\
\text { (SE) }\end{array}$ & P-value \\
\hline Fat Free Mass (kg) & $21.9(8.1)$ & 0.007 & $1.1(0.3)$ & 0.0006 & $1.1(0.4)$ & 0.007 & $2.1(1.2)$ & 0.07 \\
\hline Total Skeletal Muscle (kg) & $25.8(11.0)$ & 0.02 & $1.3(0.4)$ & 0.003 & $1.2(0.6)$ & 0.03 & $2.6(1.6)$ & 0.09 \\
\hline RMR (kcal/day) & $0.2(0.1)$ & 0.12 & $0.01(0.0)$ & 0.02 & $0.01(0.01)$ & 0.02 & $0.01(0.02)$ & 0.71 \\
\hline Body Weight (kg) & $4.6(2.9)$ & 0.12 & $0.3(0.1)$ & 0.02 & $0.4(0.2)$ & 0.002 & $-0.2(0.4)$ & 0.69 \\
\hline BMI $\left(\mathrm{kg} / \mathrm{m}^{2}\right)$ & $10.7(8.3)$ & 0.2 & $0.7(0.3)$ & 0.04 & $1.2(0.4)$ & 0.004 & $-0.6(1.2)$ & 0.58 \\
\hline Fat Mass (kg) & $1.6(3.8)$ & 0.67 & $0.1(0.1)$ & 0.44 & $0.4(0.2)$ & 0.03 & $-0.6(0.5)$ & 0.24 \\
\hline$\%$ body fat & $-6.2(7.2)$ & 0.4 & $-0.2(0.3)$ & 0.43 & $0.3(0.4)$ & 0.48 & $-2.0(1.0)$ & 0.048 \\
\hline SAT (kg) & $0.5(4.2)$ & 0.9 & $0.1(0.2)$ & 0.57 & $0.4(0.2)$ & 0.09 & $-0.8(0.6)$ & 0.19 \\
\hline $\operatorname{VAT}(\mathrm{kg})$ & $137.0(77.4)$ & 0.08 & $4.1(3.2)$ & 0.2 & $10.0(3.9)$ & 0.01 & $6.8(10.9)$ & 0.54 \\
\hline
\end{tabular}

Note: The parameter estimate (i.e. the slope coefficient) indicates the amount by which energy intake (Calories, kcal) increases per unit increase in the independent variable. For example, for each $1 \mathrm{~kg}$ increase in fat free mass the energy intake goes up by $21.9 \mathrm{kcal}$. $\mathrm{RMR}=$ resting metabolic rate; $\mathrm{kcal}=$ kilocalories; $\mathrm{kg}=$ kilograms; $\mathrm{SAT}=$ subcutaneous adipose tissue; and VAT=visceral adipose tissue; BMI, body mass index 


\section{Figure Legends}

Figure 1. Scatter plots with standardized $\beta$-coefficients showing the relationship between mean 3 day energy intake, fat mass (FM), total skeletal muscle, and resting metabolic rate (RMR). 

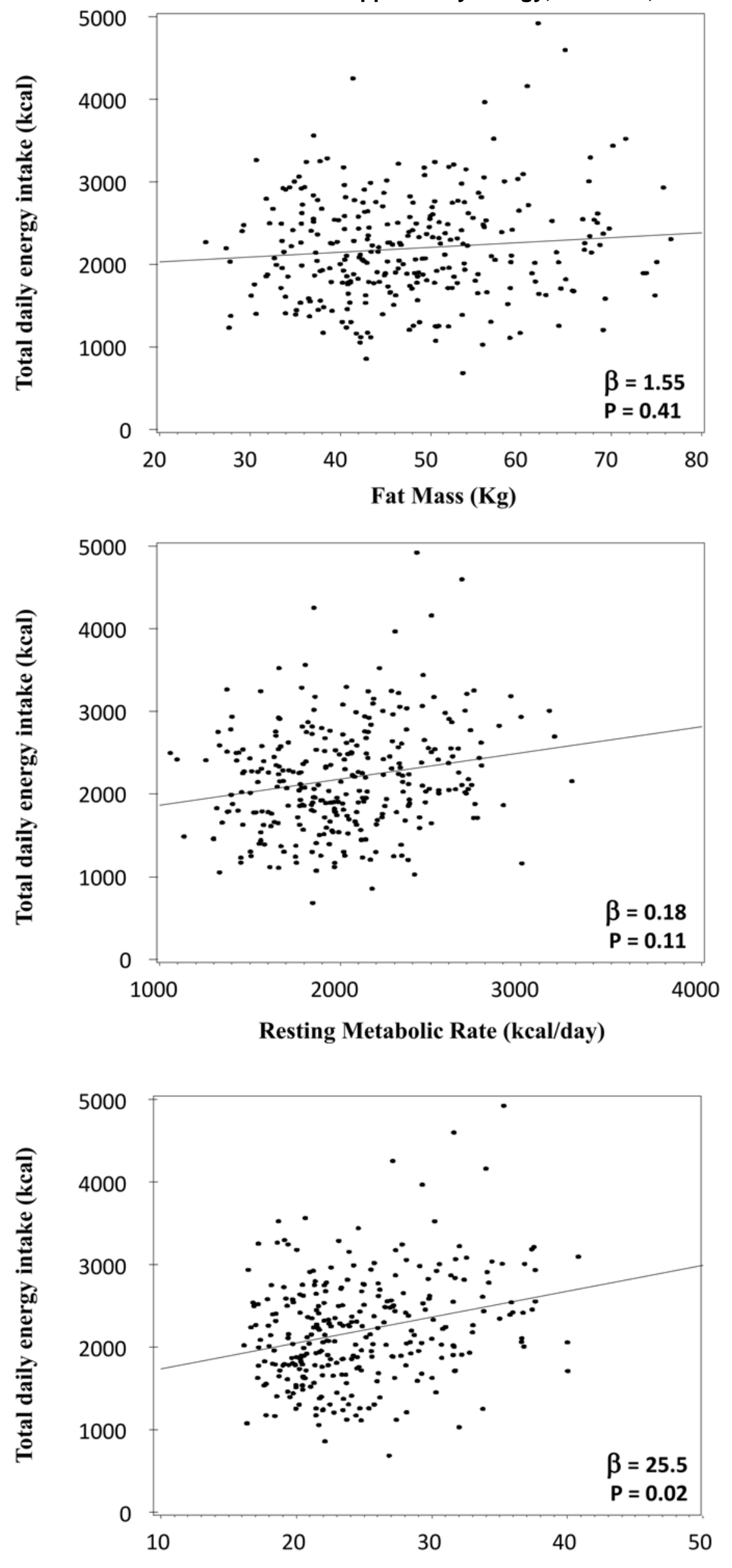

Total Skeletal Tissue (Kg) 